\title{
Jackfruit Seed-Derived Nanoporous Carbons as the Electrode Material for Supercapacitors
}

\author{
Rashma Chaudhary ${ }^{1}$, Subrata Maji ${ }^{2}$, Rekha Goswami Shrestha ${ }^{2}$, Ram Lal Shrestha ${ }^{1}$ (1), \\ Timila Shrestha ${ }^{1}$, Katsuhiko Ariga 2,3 (D) and Lok Kumar Shrestha ${ }^{2, *(\mathbb{D}}$ \\ 1 Amrit Campus, Tribhuvan University, Kathmandu 44613, Nepal; chaudharyreshma896@gmail.com (R.C.); \\ swagatstha@gmail.com (R.L.S.); timilastha@gmail.com (T.S.) \\ 2 International Center for Materials Nanoarchitectonics (WPI-MANA), \\ National Institute for Materials Science (NIMS), 1-1 Namiki, Ibaraki, Tsukuba 305-0044, Japan; \\ MAJI.Subrata@nims.go.jp (S.M.); GOSWAMI.Rekha@nims.go.jp (R.G.S.); ARIGA.Katsuhiko@nims.go.jp (K.A.) \\ 3 Graduate School of Frontier Sciences, The University of Tokyo, 5-1-5 Kashiwanoha, \\ Kashiwa, Chiba 277-8561, Japan \\ * Correspondence: SHRESTHA.Lokkumar@nims.go.jp; Tel.: +81-29-860-4809
}

Received: 16 October 2020; Accepted: 5 November 2020; Published: 6 November 2020

\begin{abstract}
Hierarchically porous activated carbon materials from agro-waste, Jackfruit seeds are prepared by a chemical activation method involving the treatment with zinc chloride $\left(\mathrm{ZnCl}_{2}\right)$ at different temperatures $\left(600-1000{ }^{\circ} \mathrm{C}\right)$. The electrochemical supercapacitance performances of the prepared materials were studied in an aqueous electrolyte ( $1 \mathrm{M}$ sulfuric acid, $\left.\mathrm{H}_{2} \mathrm{SO}_{4}\right)$ in a three-electrode system. Jackfruit seed carbons display nanoporous structures consisting of both micro- and mesopore architectures and they are amorphous in nature and also contain oxygenated surface functional groups, as confirmed by powder X-ray diffraction (pXRD), Raman scattering, and Fourier-transformed infrared (FTIR) spectroscopy, respectively. The surface areas and pore volumes were found to be 1216.0 to $1340.4 \mathrm{~m}^{2} \cdot \mathrm{g}^{-1}$ and 0.804 to $1.144 \mathrm{~cm}^{3} \cdot \mathrm{g}^{-1}$, respectively, demonstrating the better surface textural properties compared to the commercial activated carbons. Due to the high surface area, large pore volume, and well developed hierarchical micro- and mesoporosity, the optimal sample achieved a high specific capacitance of $292.2 \mathrm{~F} \cdot \mathrm{g}^{-1}$ at $5 \mathrm{mV} \cdot \mathrm{s}^{-1}$ and $261.3 \mathrm{~F} \cdot \mathrm{g}^{-1}$ at $1 \mathrm{~A} \cdot \mathrm{g}^{-1}$ followed by outstanding high rate capability. The electrode sustained $71.6 \%$ capacity retention at a high current density of $20 \mathrm{~A} \cdot \mathrm{g}^{-1}$. Furthermore, the electrode displayed exceptional cycling stability with small capacitance loss $(0.6 \%)$ even after 10,000 charging-discharging cycles, suggesting that Jackfruit seed would have potential in low-cost and scalable production of nanoporous carbon materials for supercapacitors applications.
\end{abstract}

Keywords: agricultural waste; Jackfruit seed; chemical activation; nanoporous carbon; supercapacitors

\section{Introduction}

Electrochemical energy storage devices such as batteries and supercapacitors are the key components in the significant development of renewable and sustainable energy sources. The exponential growth of small portable electronics and also large hybrid-electric devices is demanding an instant supply of energy storage systems. Currently, the storage of electrochemical energy appears to be the most cost-effective and viable way to meet the increasing demand [1-9]. Lithium-ion batteries (LIBs) and electrochemical supercapacitors (SCs) or electrical double-layer capacitors (EDLCs) have emerged as the most promising candidates [10-14]. Supercapacitors with high power density $\left(>400 \mathrm{~kW} \cdot \mathrm{kg}^{-1}\right)$ and long cycle stability $(>100,000)$ have been extensively used in high power devices such as hybrid cars, electric buses and even in a jumbo passenger plane, Airbus A380 [15-19]. 
Additionally, the high rate capability with fast charging-discharging abilities makes supercapacitors suitable for further hands-on application. With the many positive aspects, supercapacitors suffer from one major problem; lower energy density compared to Li-ion batteries [20-22]. The energy density of supercapacitors can be improved either by increasing the specific capacitance $\left(C_{S}\right)$ or increasing the potential window $(V)$ [23]. Increment in the potential window is fully dependent on the type of electrolytes, and commonly used aqueous electrolytes can provide $\sim 1.2 \mathrm{~V}$. On the other hand, specific capacitance mainly depends on the charge storage capacity of the electrode materials. Therefore, extensive investigations are going on to explore new low-cost materials with excellent charge storage capacity to attain very high specific capacitance [24-27].

Carbon-based electrode materials, specifically those resulting from nanoporous activated carbons, are extensively used as electrode materials in commercial supercapacitors owing to their high surface area, excellent chemical and thermal stabilities [28-32]. Most of the commercial activated carbons are produced from the combustion of fossil fuel-based precursors, such as coal, gasoline, pitch, etc., which is not environmentally friendly and also not economical [33-36]. Therefore, the preparation of carbon materials requires an alternative method or precursors, which can be environmentally friendly and economically sustainable. In this regard, biomass precursors have emerged as an alternative source for the preparation of activated carbons through direct carbonization or chemical activation methods. Natural biomasses are mainly composed of carbohydrate polymers (cellulose and hemicellulose) and aromatic polymers (lignin, and tannin). Additionally, these biomasses are usually rich in heteroatoms, such as nitrogen, sulfur, and phosphorus, which enables the preparation of heteroatom-doped porous carbons for enhanced energy storage $[37,38]$. Theses biomasses, upon pyrolysis at low temperatures (200-300 $\left.{ }^{\circ} \mathrm{C}\right)$, produce biochar with a very low specific surface area due to the lack of well-developed nanoporosity. However, chemical or physical activation of these biochars leads to the formation of high surface area and well-developed porous carbon materials. Recently, using biomass or various agricultural wastes such as fish scales [39], corncob [40], washnuts [41], rice husks [42], pistachio shell [43], bamboo [44], pitch [45], algae [46], batata leaves and stalks [47], peanut dregs [48], lapsi seed [49], etc., porous carbon materials were produced. These biomass-derived carbon materials exhibit high surface area and large pore volumes. Such large porosity carbon materials together with interconnected mesopore structure and uniform pore size distribution are highly demanded in supercapacitors applications. Various activating agents such as zinc chloride $\left(\mathrm{ZnCl}_{2}\right)$, sodium carbonate, phosphoric acid, potassium and sodium hydroxides are commonly used during the chemical activation process [50-53]. The selection of appropriate activating agents and proper carbonization conditions is very important to enhance the specific surface area via the development of hierarchical micro and mesopores with favorable surface functional groups. $\mathrm{ZnCl}_{2}$ dehydrates the biochar and boosts the decomposition process, and enhances the yield of carbon via the reduction in tar content.

In this contribution, low-cost and scalable preparation of hierarchical nanoporous activated carbon materials from agro-waste, namely Jackfruit seeds, via the $\mathrm{ZnCl}_{2}$ activation method is reported, and their electrochemical energy storage capacity is studied in $1 \mathrm{M} \mathrm{H}_{2} \mathrm{SO}_{4}$ in a three-electrode system at $25{ }^{\circ} \mathrm{C}$. First, Jackfruit seed powder was heated (pre-carbonized) at $300{ }^{\circ} \mathrm{C}$ in the air to obtain the biochar, which was then chemically activated, impregnating with $\mathrm{ZnCl}_{2}$ at a 1:1 weight ratio, and carbonized at different temperatures from 600 to $1000{ }^{\circ} \mathrm{C}$ under a constant flux of nitrogen gas $\left(120 \mathrm{cc} \cdot \mathrm{min}^{-1}\right)$. Jackfruit seed-derived activated carbons were characterized by scanning electron microscopy, powder X-ray diffraction, Fourier-transformed infrared (FTIR) spectroscopy, and Raman scattering. Surface textural properties, namely surface area, pore volume, and pore size distribution, were determined by nitrogen adsorption-desorption isotherms. Electron microscopy and nitrogen sorption isotherms revealed that the prepared carbon materials show hierarchical porous architecture consisting of both micro- and mesoporous architecture. The optimal sample exhibits a high specific surface area $\left(1340.4 \mathrm{~m}^{2} \cdot \mathrm{g}^{-1}\right)$ and a large pore volume $\left(1.144 \mathrm{~cm}^{3} \cdot \mathrm{g}^{-1}\right)$. Owing to the high surface area, large pore volume, and well-developed micro- and mesoporosity, the optimal sample showed excellent electrochemical charge storage capacity achieving a high specific capacitance of $292.2 \mathrm{~F} \cdot \mathrm{g}^{-1}$ at $5 \mathrm{mV} \cdot \mathrm{s}^{-1}$ 
and $261.3 \mathrm{~F} \cdot \mathrm{g}^{-1}$ at $1 \mathrm{~A} \cdot \mathrm{g}^{-1}$. The observed high capacity retention of $71.6 \%$ at a high current density of $20 \mathrm{~A} \cdot \mathrm{g}^{-1}$ demonstrates the outstanding rate capability of the electrode material. Furthermore, the electrode showed excellent performance on cyclic stability test and retained $99.4 \%$ capacity after 10,000 charging-discharging cycles. These results suggest that the agro-waste Jackfruit seed would be a suitable precursor material for the scale-up synthesis of hierarchically porous activated carbon materials that can be used as the electrode materials in supercapacitors.

\section{Materials and Methods}

\subsection{Preparation of Nanoporous Activated Carbons}

The natural biomass Jackfruit seed collected from the local market was cleaned several times with distilled water, oven-dried at $80{ }^{\circ} \mathrm{C}$ for $12 \mathrm{~h}$, crushed into the powder in a mechanical grinder, and heated at $300{ }^{\circ} \mathrm{C}$ (pre-carbonized) in the air for $3 \mathrm{~h}$ to obtain biochar. Pre-carbonized biochar was mixed with $\mathrm{ZnCl}_{2}$ at a $1: 1$ weight ratio and carbonized at 600,800 , and $1000^{\circ} \mathrm{C}$ under the nitrogen flow $\left(120 \mathrm{cc} \cdot \mathrm{min}^{-1}\right)$ in a tube furnace (KOYO, Tokyo, Japan). During the carbonization, the temperature ramp was set to $5{ }^{\circ} \mathrm{C} \mathrm{min}^{-1}$ with a hold time of $3 \mathrm{~h}$. The as-prepared activated carbons were then treated with $0.5 \mathrm{M}$ aqueous hydrochloric acid solution to remove unreacted zinc chloride. The obtained materials were further washed with distilled water to remove excess acid. Finally, the obtained carbon materials were vacuum dried at $80{ }^{\circ} \mathrm{C}$ for $6 \mathrm{~h}$ and further ground into fine particles. Depending on the carbonization temperature, $\mathrm{ZnCl}_{2}$ activated carbon samples were referred to as JFSC_Z600, JFSC_Z800, and JFSC_Z1000. As a control sample, Jackfruit seed powder was directly carbonized at $800{ }^{\circ} \mathrm{C}$ without $\mathrm{ZnCl}_{2}$ and the derived carbon was referred to as JFS_800.

\subsection{Characterizations}

The prepared Jackfruit carbon materials were characterized by scanning electron microscopy (SEM: S-4800, Hitachi Co. Ltd., Tokyo, Japan), powder X-ray diffraction (XRD: Rigaku X-ray diffractometer, RINT, Tokyo, Japan), Raman scattering (NRS-3100, JASCO, Tokyo, Japan), and Fourier-transformed infrared (FTIR) spectroscopy (Nicolet 4700, Thermo Electron Corporation, Waltham, MA, USA). Surface textural properties (surface areas, pore volumes, average pore sizes, and pore size distributions) were determined by recording nitrogen adsorption-desorption isotherms at liquid nitrogen temperature $77.35 \mathrm{~K}$ on the Quantachrome Autosorb-iQ2, Boynton Beach, FL, USA: an automatic adsorption instrument. The carbon sample $(\sim 30 \mathrm{mg})$ was degassed at $120^{\circ} \mathrm{C}$ for $24 \mathrm{~h}$ before the measurements. From the nitrogen adsorption isotherms, Brunauer-Emmett-Teller (BET) surface areas were estimated. The pore size distributions were determined by the Barrett-Joyner-Halenda method (BJH method: for mesopore) method and density functional theory (DFT method: for micropore). The DFT method is based on the independent pore model proposed by Seaton et al. [54]. The adsorption isotherm can be represented as a set of independent non-interconnected pores. Since nanoporous activated carbons have slit-shaped pores, the experimental adsorption isotherm $\mathrm{N}(P)$ represents an average of all the pore sizes existing in the material and can be expressed as:

$$
\mathrm{N}(P)=\int_{H_{\min }}^{H_{\max }} \rho(P, H) f(H) \mathrm{d} H
$$

where $H_{\min }$ and $H_{\max }$ are the smallest and largest pore widths, $\rho(P, H)$ is the mean density of the adsorbed nitrogen in the pore width of $H$ at pressure $P$, and $f(H)$ represents the pore size distributions, which is the distribution of pore volumes as a function of the pore width of the nanoporous carbon materials. Detailed calculations of the DFT method can be found elsewhere $[55,56]$. 


\subsection{Electrochemical Measurements}

Using cyclic voltammetry (CV) and galvanostatic charge-discharge (GCD) measurements, the electrochemical energy storage capacity of the Jackfruit seed-derived carbons was studied in a three-electrode setup in an aqueous electrolyte solution $\left(1 \mathrm{M} \mathrm{H}_{2} \mathrm{SO}_{4}\right)$ at $25^{\circ} \mathrm{C}$. Glassy carbon electrode (GCE, the geometric surface area of $7.85 \mathrm{~mm}^{2}$, ALS Co., Ltd. Tokyo, Japan) was modified and used as the working electrode, while a platinum wire and $\mathrm{Ag} / \mathrm{AgCl}$ electrodes were used as counter and the reference electrode, respectively. GCE was modified with Jackfruit seed carbons as follows. First, using alumina $\left(\mathrm{Al}_{2} \mathrm{O}_{3}\right)$ slurry GCE was mirror polished and washed with distilled water and dried at $60^{\circ} \mathrm{C}$ for $3 \mathrm{~h}$. Suspensions of the carbon samples were prepared by dispersing them in a water-ethanol (4:1) solvent mixture $\left(1 \mathrm{mg} \cdot \mathrm{mL}^{-1}\right)$. The mixture was sonicated for $60 \mathrm{~min}$ in a bath sonicator (BRANSON 3510, Hampton, NH, USA). The suspension $(3 \mu \mathrm{L})$ was drop cast onto the GCE surface and dried at $60{ }^{\circ} \mathrm{C}$ for $6 \mathrm{~h}$ to remove the solvent, and a Nafion solution ( $5 \mu \mathrm{L}: 5 \%$ in ethanol) was then added as a binder and dried at $80{ }^{\circ} \mathrm{C}$ in a vacuum for $12 \mathrm{~h}$. The mass of the electrode materials was determined by the quartz crystal microbalance (QCM: $9 \mathrm{MHz}$, AT-cut, Affinix QN pro; Initium, Tokyo, Japan) technique. $\mathrm{CV}$ and $\mathrm{CD}$ profiles were recorded on a $\mathrm{CHI}$ 850D workstation ( $\mathrm{CH}$ Instruments, Inc. Austin, TX, USA) at $25^{\circ} \mathrm{C}$. Electrochemical impedance spectroscopy (EIS) measurements of the prepared carbon materials were performed on a $\mathrm{CHI} 660 \mathrm{E}$ electrochemical workstation ( $\mathrm{CH}$ Instruments, Inc. Austin, TX, USA) at $25^{\circ} \mathrm{C}$ at an open-circuit potential within the frequency range of $10^{-2}-10^{5} \mathrm{~Hz}$ at an amplitude of $5 \mathrm{mV}$.

Specific capacitances $\left(C_{S}\right)$ of the carbon materials were calculated from both $\mathrm{CV}$ and $\mathrm{CD}$ measurements. From curves, $C_{S}$ were calculated as:

$$
C_{\mathrm{s}}=\frac{1}{v \cdot m \cdot \Delta V} \int I d V
$$

where $I, v, m$, and $\Delta V$ indicate the current $(\mathrm{A})$, scan rate $\left(\mathrm{V} \cdot \mathrm{s}^{-1}\right)$, mass of active electrode materials $(\mathrm{g})$, and the operating potential window $(V)$, respectively.

From $C D$ curves, $C_{S}$ were calculated as:

$$
C_{\mathrm{s}}=\frac{I \cdot t}{m \cdot \Delta V}
$$

where $I$ is the discharge current (A), $t$ is the discharge time (s), $m$ is the mass of the active electrode material (g), and $\Delta V$ is the potential window $(\mathrm{V})$.

\section{Results and Discussion}

Figure 1 shows the representative SEM images of the directly carbonized Jackfruit seed carbon (JFS_800) and $\mathrm{ZnCl}_{2}$ activated carbon materials (JFSC_Z600, JFSC_Z800, and JFSC_Z1000) both at lowand high-resolution modes.

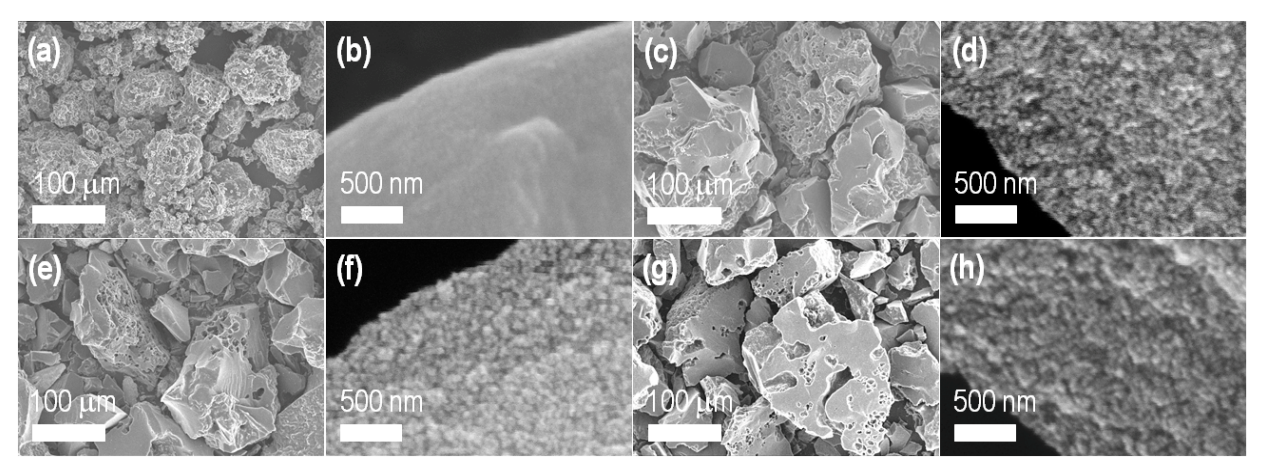

Figure 1. SEM images of the prepared nanoporous activated carbons from Jack fruit seed: (a,b) JFS_800; (c,d) JFSC_Z600; (e,f) JFSC_Z800; (g,h) JFSC_Z1000. 
Irregular granules with interconnected macropore channels are the common surface morphology of the prepared activated carbons (Figure 1c,e,g). Macropores are less obvious in the direct carbonized sample (Figure 1a). A high-resolution SEM image of the JFS_800 sample (Figure 1b) does not have any micro/mesoporous structures, while $\mathrm{ZnCl}_{2}$ activated samples have an obvious porous structure with uniform and interconnected mesoporous structure (Figure 1d,f,h), suggesting that the direct carbonization of Jackfruit seed powder does not produce porosity in the carbon framework. The interconnected mesoporous structure is common in all the activated carbons, irrespective of the carbonization temperature. During the carbonization process at higher temperatures, $\mathrm{ZnCl}_{2}$ promotes the decomposition of the carbonaceous precursors resulting in the formation of highly nanoporous carbons.

Figure 2a shows the pXRD patterns of the Jackfruit seed-derived carbon materials. All the samples show the characteristic feature of amorphous carbon with characteristic broad peaks at diffraction angles of approximately 23 and $43^{\circ}$, which correspond to (002) and (100) planes of the graphitic carbons commonly observed in carbonaceous precursors derived activated carbons [57]. A broad XRD peak corresponding to the (002) plane suggests the poorly ordered amorphous structure of the Jackfruit seed-derived carbons. The amorphous structure of the prepared carbon materials is further confirmed by the Raman scattering spectra (Figure 2b). All the samples exhibit two distinctive Raman bands approximately at 1350 and $1588 \mathrm{~cm}^{-1}$, corresponding to the $D$ and $G$ bands, respectively. The $D$ band represents the disordered structure of carbon induced by defects and impurities due to high-temperature carbonization and the $G$ band represents the ordered graphitic layer structure. To confirm the graphitization degree of the samples, the intensity ratio of $G$ and $D$ band $\left(I_{G} / I_{D}\right)$ was calculated and it was found to be 0.99 to 1.04, which indicates the formation of amorphous graphitic carbon with a minimal degree of defects, as in commercially available activated carbon materials $[57,58]$.
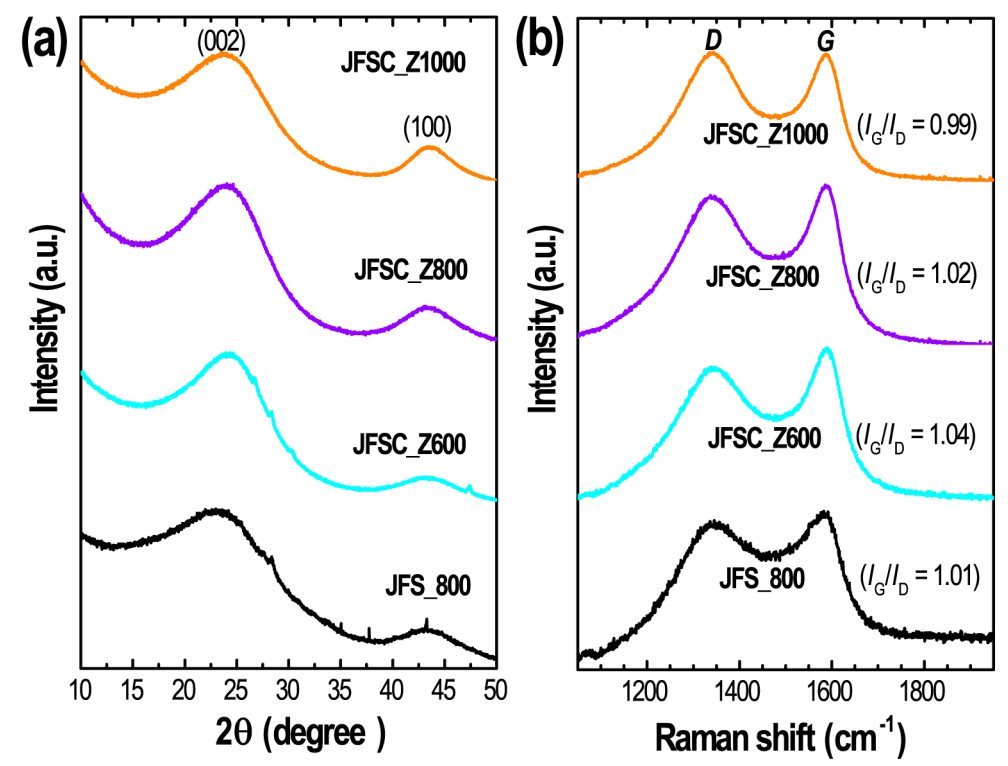

Figure 2. (a) The pXRD patterns of JFS_800, JFSC_Z600, JFSC_Z800 and JFSC_Z1000 measured at $25^{\circ} \mathrm{C}$.

(b) Raman scattering spectra of JFS_800, JFSC_Z600, JFSC_Z800 and JFSC_Z1000 recorded at $25^{\circ} \mathrm{C}$.

Surface functional groups of the precursor (Jackfruit seed powder) and the derived carbon materials were confirmed by FTIR spectroscopy. The FTIR spectrum of the Jackfruit seed powder precursor (Figure 3a) shows oxygenated functional groups $(-\mathrm{OH}, \mathrm{C}=\mathrm{O}, \mathrm{COOH}$, ether, phenol and lactones) [41,42]. The board vibration peak at $3428 \mathrm{~cm}^{-1}$ indicates the presence of alcoholic or phenolic $-\mathrm{OH}$ group. 

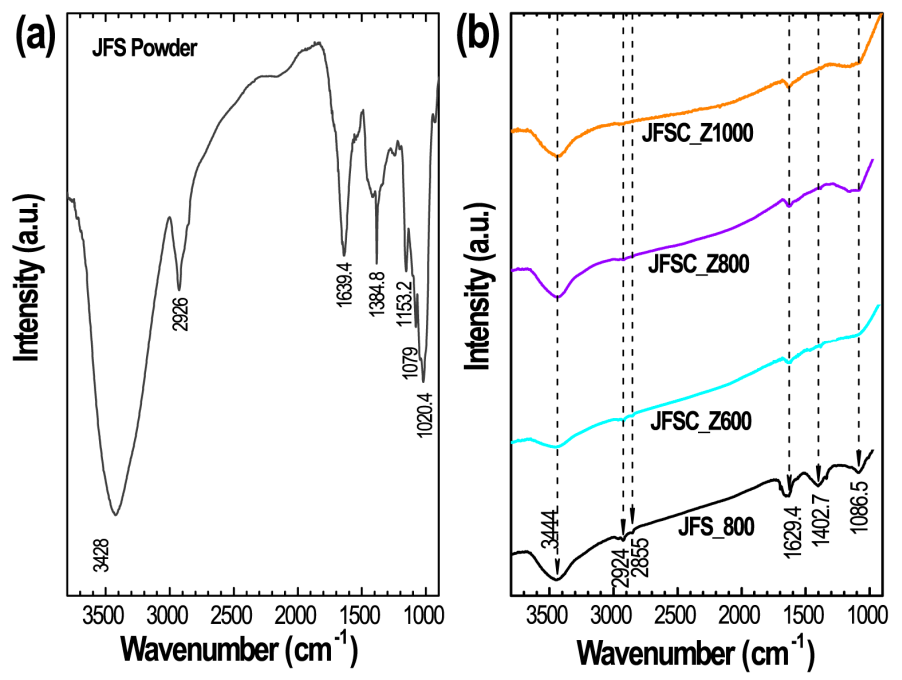

Figure 3. (a) FTIR spectrum of Jackfruit seed precursor recorded at $25^{\circ} \mathrm{C}$. (b) FTIR spectra of derived carbons JFS_800, JFSC_Z600, JFSC_Z800 and JFSC_Z1000 recorded at $25^{\circ} \mathrm{C}$.

Additionally, absorption bands at $2926 \mathrm{~cm}^{-1}$ corresponds to the aromatic ring, and the peak at $1639 \mathrm{~cm}^{-1}$ can be assigned to the $\mathrm{C}=\mathrm{O}$ stretching vibrations of the groups referring to ketones, carboxyl acids and aldehydes. The new FTIR peak at $1384 \mathrm{~cm}^{-1}$ may be assigned for $\mathrm{S}=\mathrm{O}$ group of the Jackfruit seed biomass. After the high-temperature direct carbonization of the Jackfruit seed powder and $\mathrm{ZnCl}_{2}$ activation, the obtained carbon materials could retain some of these oxygen-containing surface functional groups (Figure $3 \mathrm{~b}$ ). A broad peak centered at $3444 \mathrm{~cm}^{-1}$ suggests the presence of $\mathrm{O}-\mathrm{H}$ functional groups and a weak peak at $1629 \mathrm{~cm}^{-1}$ can be assigned to the aromatic $\mathrm{C}=\mathrm{C}$ stretching vibration, which is often detected in activated carbons.

Figure 4 a shows the nitrogen adsorption-desorption isotherms of the prepared carbon materials. The directly carbonized sample (JFS_800) display Type-III isotherm, which is an indication of nonporous or macroporous structure, which is in consistent with the SEM observations. Meanwhile, $\mathrm{ZnCl}_{2}$ activated carbon materials (JFSC_Z600, JFSC_Z800, and JFSC_Z1000) exhibit a mixed Type-I/Type-IV isotherms inferring the hierarchical micro- and mesoporous structure [59]. Excessive nitrogen adsorption at a low relative pressure confirms a large number of micropores. The hysteresis loop at high relative pressure indicates the existence of mesopores.

Figure $4 \mathrm{~b}, \mathrm{c}$, respectively, show the pore size distribution profiles obtained from the $\mathrm{BJH}$ and DFT methods, which further confirm the existence of micro- and mesopores architecture in the $\mathrm{ZnCl}_{2}$ activated carbons. Moreover, the presence of micro- and mesopore in all the $\mathrm{ZnCl}_{2}$ activated carbons is in favor of enhancing the synergistic effects between pores of different sizes and providing more channels for ion/electrolyte transfer in high-energy storage systems. Table 1 summarizes the surface area, pore volumes, and average pore diameters of the prepared nanoporous carbon materials.

Table 1. Surface textural properties of nanoporous activated carbons obtained from Jackfruit seed.

\begin{tabular}{|c|c|c|c|c|c|c|}
\hline Carbon Sample & $\begin{array}{c}S S A \\
\left(\mathrm{~m}^{2} \cdot \mathrm{g}^{-1}\right)\end{array}$ & $\begin{array}{c}S_{\text {micro }} \\
\left(\mathrm{m}^{2} \cdot \mathrm{g}^{-1}\right)\end{array}$ & $\begin{array}{c}S_{\text {meso }} \\
\left(\mathrm{m}^{2} \cdot \mathrm{g}^{-1}\right)\end{array}$ & $\begin{array}{c}V_{\mathrm{p}} \\
\left(\mathrm{cm}^{3} \cdot \mathrm{g}^{-1}\right)\end{array}$ & $\begin{array}{c}V_{\text {micro }} \\
\left(\mathrm{cm}^{3} \cdot \mathrm{g}^{-1}\right)\end{array}$ & $\begin{array}{c}D_{\text {meso }} \\
(\mathrm{nm})\end{array}$ \\
\hline JFS_800 & 58.7 & 23.3 & 35.4 & 0.122 & 0.055 & 3.09 \\
\hline JFSC_Z600 & 1216.0 & 1101.6 & 114.4 & 0.804 & 0.639 & 3.10 \\
\hline JFSC_Z800 & 1340.4 & 1214.7 & 125.7 & 1.144 & 0.958 & 3.09 \\
\hline JFSC_Z1000 & 1321.4 & 1149.9 & 171.5 & 0.965 & 0.704 & 3.10 \\
\hline
\end{tabular}

$S S A, S_{\text {micro, }}$ and $S_{\text {meso }}$ respectively represents specific, micropore, and mesopore surface area, $V_{\mathrm{p}}$, and $V_{\text {micro }}$, represents total and micropore volume as obtained from the DFT method, $D_{\text {meso }}$ represents the average mesopore diameter as obtained from the BJH method. 

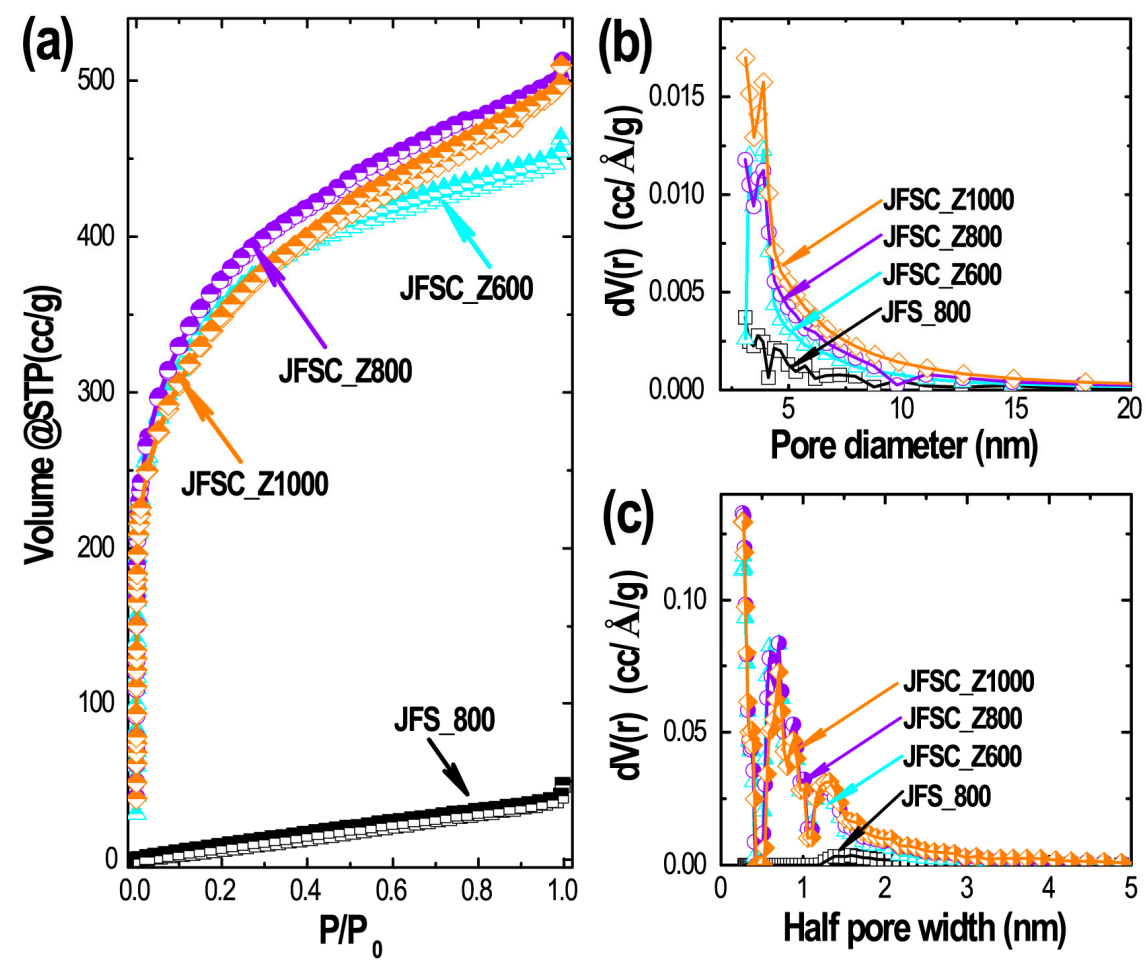

Figure 4. (a) Nitrogen adsorption isotherm of derived carbons JFS_800, JFSC_Z600, JFSC_Z800 and JFSC_Z1000 measured at77 K. (b) Pore size distributions profiles obtained by the Barrett-Joyner-Halenda (BJH) method. (c) Pore size distributions profiles obtained by the density functional theory (DFT) method.

Using cyclic voltammetry (CV) and chronopotentiometry, the electrochemical charge storage capacity of the prepared carbon materials was studied. Figure 5a shows a comparison of the CV curves at a fixed scan rate of $50 \mathrm{mV} \cdot \mathrm{s}^{-1}$. All the $\mathrm{CV}$ curves display a quasi-rectangular shape, suggesting the EDLC type of charge storage mechanism $[57,60]$.

The total integral current output is different depending on the sample and follows the following order, JFSC_Z800 > JFSC_Z1000 > JFSC_Z600 > JFS_800, which is in agreement with the surface textural properties suggesting that the higher the specific surface area better the energy storage capacity (Table 1 ). Due to the high micropore surface area, the JFSC_Z800 sample offers plenty of sites for the formation of the electrical double layer together with the fast electrolyte ion diffusion promoted by the mesoporous structure. Figure $5 \mathrm{~b}$-e show the $\mathrm{CV}$ profiles of the directly carbonized sample without $\mathrm{ZnCl}_{2}, \mathrm{JFS} \_800$ (Figure 5b), and chemically ( $\left.\mathrm{ZnCl}_{2}\right)$ activated samples JFSC_Z600 (Figure 5c), JFSC_Z800 (Figure 5d), and JFSC_Z1000 (Figure 5e) at different scan rates starting from 5 to $500 \mathrm{mV} \cdot \mathrm{s}^{-1}$. CV profiles of all the samples show that the total current increases with increasing the scan rate and quasi-rectangular shape are retained up to a high scan rate of $500 \mathrm{mV} \cdot \mathrm{s}^{-1}$, suggesting fast charge propagation kinetics with excellent reversibility even at a very high scan rate of $500 \mathrm{mV} \cdot \mathrm{s}^{-1}$. Figure $5 \mathrm{f}$ compares the specific capacitance $\left(C_{S}\right)$ calculated from the $\mathrm{CV}$ curves for all the carbon samples. As expected, due to the low surface area and small porosity, the directly carbonized sample showed poor supercapacitance performance. The specific capacitance was ca. $19.6 \mathrm{~F} \cdot \mathrm{g}^{-1}$ at $5 \mathrm{mV} \cdot \mathrm{s}^{-1}$, while the $\mathrm{ZnCl}_{2}$ activated samples showed excellent specific capacitances. The optimal sample JFSC_Z800 achieved the highest specific capacitance of $292.2 \mathrm{~F} \cdot \mathrm{g}^{-1}$ at a scan rate $5 \mathrm{mV} \cdot \mathrm{s}^{-1}$, retaining $77.8 \%$ capacitance retention even at a high scan rate of $500 \mathrm{mV} \cdot \mathrm{s}^{-1}$. Specific capacitances of JFSC_Z600 and JFSC_Z1000 were ca. 171.7 and $214.7 \mathrm{~F} \cdot \mathrm{g}^{-1}$, respectively. 

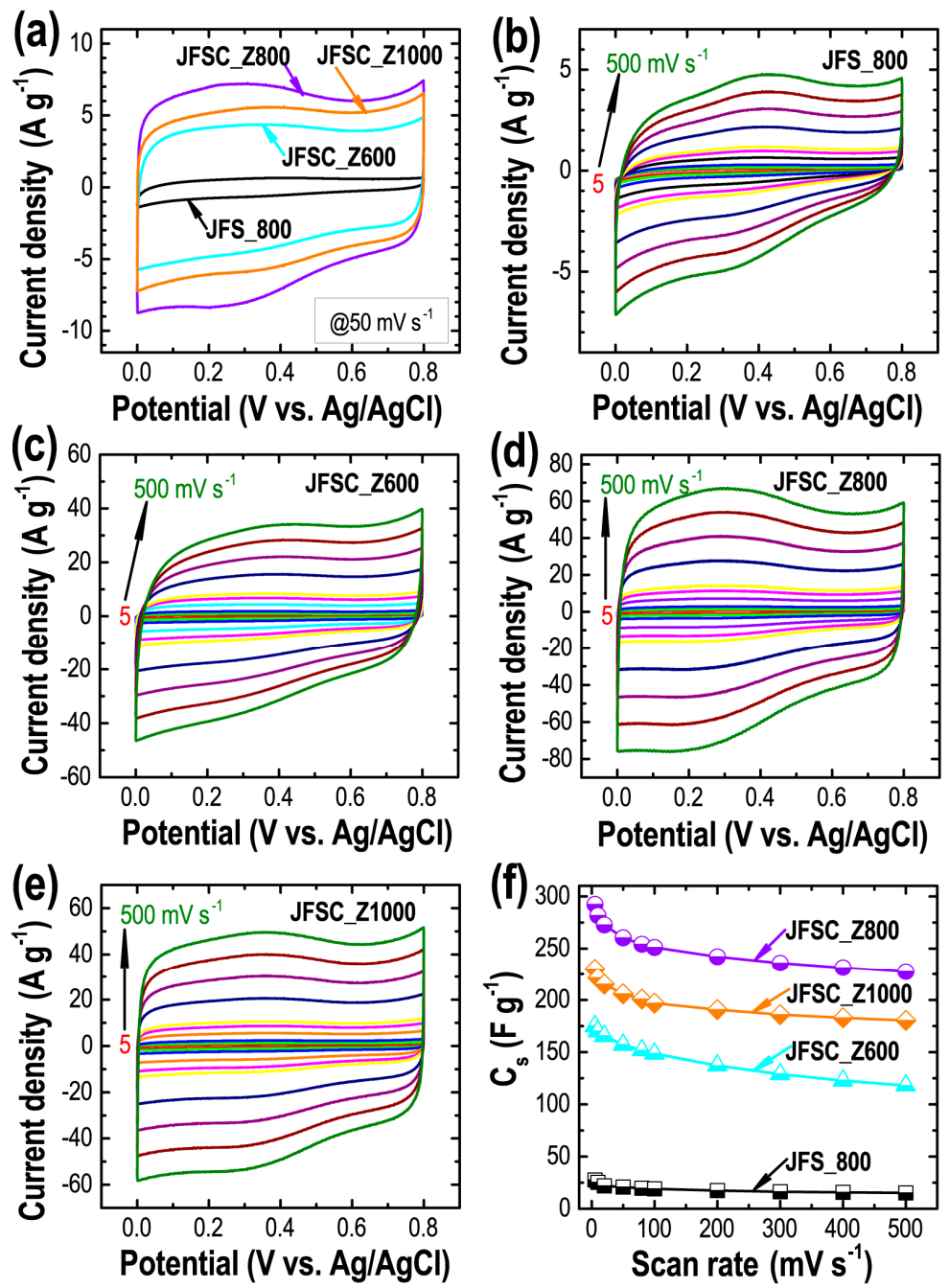

Figure 5. (a) Comparison of cyclic voltammetry (CV) profiles of all the derived nanoporous carbons at fixed scan rate $5 \mathrm{mV} \cdot \mathrm{s}^{-1}$, and the $\mathrm{CV}$ profiles at different scan rate $5-500 \mathrm{mV} \cdot \mathrm{s}^{-1}$. (b) JFS_800, (c) JFSC_Z600, (d) JFSC_Z800, and (e) JFSC_Z1000. (f) Calculated specific capacitance vs. scan rate for all the samples.

Figure 6 shows the results obtained from the galvanostatic charge-discharge (CD) measurements. Comparison of CD profiles at a fixed current density of $1 \mathrm{~A} \cdot \mathrm{g}^{-1}$ exhibit triangular shape of CD curves (Figure 6a), which a the typical characteristic of the EDLC behavior of the carbon electrodes [57,61-63]. The linear decay of the discharge curves is an indication of the well-balanced charge storage. The shorter discharge time of the directly carbonized samples indicates the poorer energy storage capacity of the material compared to the $\mathrm{ZnCl}_{2}$ activated samples. The best sample (JFSC_Z800) exhibits the longest discharge time, indicating the maximum energy storage capacity of the material compared to JFSC_Z600 and JFSC_Z1000. Figure 6b-d show the CD profiles for JFS_800, JFSC_Z800 and JFSC_Z1000, respectively. The triangular shape of the $\mathrm{CD}$ profiles persisted at high current density, indicating good electrochemical energy storage performances. Using Equation (3), specific capacitances were ca. $19.6 \mathrm{~F} \cdot \mathrm{g}^{-1}$ (JFS_800), $171.7 \mathrm{~F} \cdot \mathrm{g}^{-1}$ (JFSC_Z600), $261.3 \mathrm{~F} \cdot \mathrm{g}^{-1}$ (JFSC_Z800) and 214.7 (JFSC_1000) at 1 A.g ${ }^{-1}$. Specific capacitances vs. current density curves for all the samples are shown in Figure 6e. The higher capacitance of the JFSC_Z800 sample is caused due to the high specific surface (particularly micropore surface area) and large pore volume compared to the rest of the samples. 

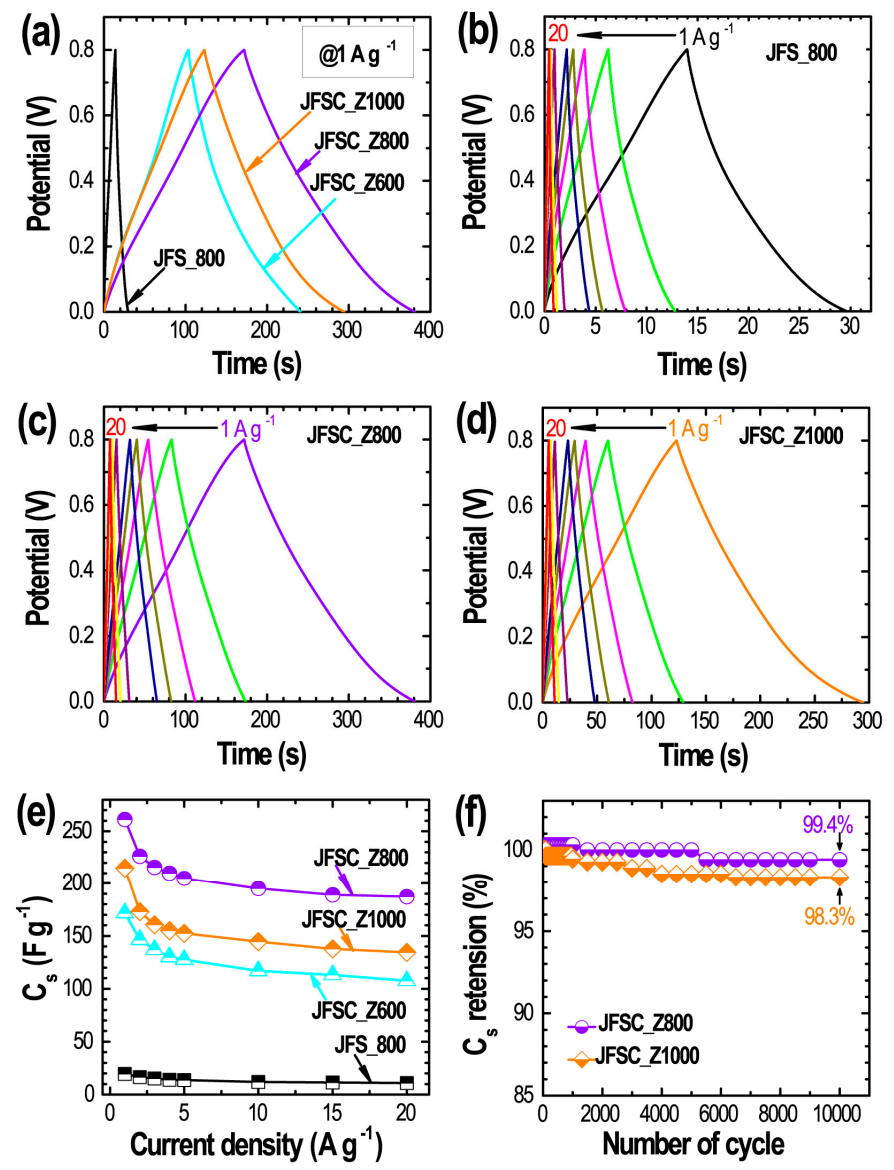

Figure 6. (a) Comparison of charge-discharge (CD) profiles of Jackfruit seed nanoporous carbons at

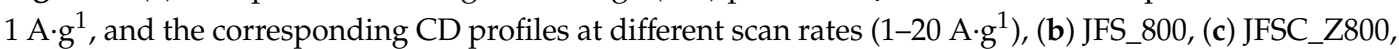
(d) JFSC_Z1000, (e) Calculated specific capacitance from CD profiles ad different current density, and (f) Cycling stability for JFSC_Z800 and JFSC_Z1000 up to 10,000 charging-discharging cycles.

Capacitance retention for all the activated samples is more than $62 \%$ at a high current density of $20 \mathrm{~A} \cdot \mathrm{g}^{-1}$ with the optimal sample achieving outstanding capacity retention of $77.8 \%$. Furthermore, the electrode shows admirable cycling stability at the cost of only $0.6 \%$ capacity loss after 10,000 charging-discharging cycles (Figure 6f). The cyclic stability of JFSC_Z1000 is comparable with the optimal samples.

Figure 7 shows Nyquist plots of the prepared carbon materials obtained from the EIS measurements. The plots show ideal EDLC behavior with poor semicircular behavior in the high frequency region.
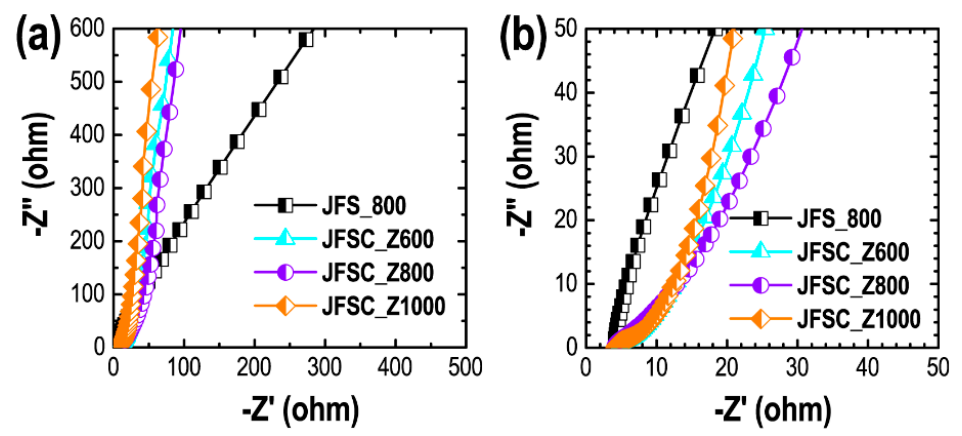

Figure 7. (a) Nyquist plots obtained from EIS measurements of JFS_800, JFSC_Z600, JFSC_Z800, and JFSC_Z1000 in an aqueous electrolyte $\left(1 \mathrm{M} \mathrm{H}_{2} \mathrm{SO}_{4}\right)$, (b) corresponding magnified plots. 
A sharp rise of the curves in the chemically activated sample at the lower frequency region demonstrates the fast electrolyte ion transport within the electrode materials due to high porosity. The slow ion transport in the directly carbonized sample can be attributed to the lack of well-developed porosity. From the intersection point on the real axis, the equivalent series resistances (ESR) were ca. $4.18 \Omega$ (JFS_800), $4.26 \Omega$ (JFSC_Z600), $3.95 \Omega$ (JFSC_Z800), and $4.11 \Omega$ (JFSC_Z1000), which demonstrates that the optimal sample exhibits lowest ESR. Generally, high mass loading $(\sim 10 \mathrm{mg})$ and a two-electrode system are required to get more accurate and practical information on the capability of the materials in the electrochemical energy storage performance (energy density and power density) of the supercapacitor devices $[64,65]$. Nevertheless, our results obtained from the electrochemical measurements suggest that $\mathrm{ZnCl}_{2}$ activated Jackfruit seed carbons due to hierarchical micro- and mesopore architecture serves as the high rate capability long cycling life electrode materials for supercapacitors applications.

\section{Conclusions}

In conclusion, hierarchical micro- and mesoporous carbon materials have been prepared from Jackfruit seeds by the chemical activation method using $\mathrm{ZnCl}_{2}$ as the dehydrating agent, and their electrochemical energy storage capacity performance was studied in $1 \mathrm{M}$ sulfuric acid aqueous electrolyte solution by cyclic voltammetry and chronopotentiometry. Pre-carbonized Jackfruit seed powder impregnated with $\mathrm{ZnCl}_{2}$ (1:1 weight ratio) upon carbonization at higher temperatures $\left(600-1000{ }^{\circ} \mathrm{C}\right)$ resulted in the formation of highly porous carbon materials with a hierarchically structured micro- and mesoporous structure. The specific surface areas and pore volumes found in the range of $1216-1340 \mathrm{~m}^{2} \cdot \mathrm{g}^{-1}$ and $0.804-1.114 \mathrm{~cm}^{3} \cdot \mathrm{g}^{-1}$, respectively, which is much higher than the conventional active carbon and the directly carbonized Jackfruit seed carbon without activating agent. Owing to the high surface area and well-developed porosity with the hierarchical nanoporous structure, Jackfruit seed carbons showed excellent supercapacitance performance concerning specific capacitance, capacitance retention, rate capability, and cycle life. The electrode prepared with the optimal sample achieved a high specific capacitance of $292.2 \mathrm{~F} \cdot \mathrm{g}^{-1}$ at $5 \mathrm{mV} \cdot \mathrm{s}^{-1}$ and $261.3 \mathrm{~F} \cdot \mathrm{g}^{-1}$ at $1 \mathrm{~A} \cdot \mathrm{g}^{-1}$. Capacitance retention was ca. $77.8 \%$ at a high scan rate of $500 \mathrm{mV} \cdot \mathrm{s}^{-1}$, and rate capability was ca. $71.6 \%$ at a high current density of $20 \mathrm{~A} \cdot \mathrm{g}^{-1}$ followed by outstanding cycling life sustaining $99.4 \%$ capacitance after 10,000 charging-discharging cycles. These results suggest that Jackfruit seed agro-waste would be suitable for low-cost precursor materials for the green synthesis of high-surface area nanoporous carbon materials for potential use in advanced supercapacitor applications.

Author Contributions: Conceptualization, L.K.S. and R.G.S.; methodology, L.K.S., R.L.S., T.S., R.G.S.; validation, L.K.S., R.G.S. and S.M.; investigation, R.C., T.S., S.M., R.G.S., and R.L.S.; data curation, L.K.S., R.C., and S.M.; writing - original draft preparation, R.C.; S.M. and R.G.S; writing-review and editing, L.K.S., and K.A.; supervision, L.K.S. and K.A.; project administration, L.K.S.; funding acquisition, L.K.S. and K.A. All authors have read and agreed to the published version of the manuscript.

Funding: This work is partially supported by supported by JSPS KAKENHI Grant Number JP $16 \mathrm{H} 06518$ and 20K05590 and CREST JST Grant Number JPMJCR1665.

Acknowledgments: Rashma Chaudhary and Timila Shrestha thank the International Center for Materials Nanoarchitectonics (WPI-MANA), National Institute for Materials Science (NIMS) for the Internship award for the period of 17 February to 12 July 2020 (R.C.) and August 18 to September 14, 2019 and January 6 to January 28, 2020 (T.S.).

Conflicts of Interest: The authors declare no conflict of interest.

\section{References}

1. Wang, X.; Salari, M.; Jiang, D.-e.; Varela, J.C.; Anasori, B.; Wesolowski, D.J.; Dai, S.; Grinstaff, M.W.; Gogotsi, Y. Electrode material-ionic liquid coupling for electrochemical energy storage. Nat. Rev. Mater. 2020, 5, 787-808. [CrossRef]

2. Shrestha, R.G.; Maji, S.; Shrestha, L.K.; Ariga, K. Nanoarchitectonics of nanoporous carbon materials in supercapacitors applications. Nanomaterials 2020, 10, 639. [CrossRef] 
3. Zhang, C.; Zhang, L.; Yu, G. Eutectic electrolytes as a promising platform for next-generation electrochemical energy storage. Acc. Chem. Res. 2020, 53, 1648-1659. [CrossRef] [PubMed]

4. Lin, Y.; Chem, Z.; Yu, C.; Zhong, W. Facile synthesis of high nitrogen-doped content, mesopore-dominated biomass-derived hierarchical porous graphitic carbon for high performance supercapacitors. Electrochim. Acta 2020, 334, 135615.

5. Hou, J.; Shao, Y.; Ellis, M.W.; Moore, R.B.; Yi, B. Graphene-based electrochemical energy conversion and storage: Fuel cells, supercapacitors and lithium ion batteries. Phys. Chem. Chem. Phys. 2011, 13, 15384-15402. [CrossRef] [PubMed]

6. Sun, H.; Zhu, J.; Baumann, D.; Peng, L.; Xu, Y.; Shakir, I.; Huang, Y.; Duan, X. Hierarchical 3D electrodes for electrochemical energy storage. Nat. Rev. Mater. 2019, 4, 45-60. [CrossRef]

7. Fang, Z.; Li, P.; Yu, G. Gel electrocatalysts: An emerging material platform for electrochemical energy conversion. Adv. Mater. 2020, 32, 2003191. [CrossRef]

8. Chang, P.; Mei, H.; Zhou, S.; Dassios, K.G.; Cheng, L. 3D printed electrochemical energy storage devices. J. Mater. Chem. A 2019, 7, 4230-4258. [CrossRef]

9. Yuan, M.; Guo, X.; Liu, Y.; Pang, H. Si-based materials derived from biomass: Synthesis and applications in electrochemical energy storage. J. Mater. Chem. A 2019, 7, 22123-22147. [CrossRef]

10. Shao, Y.; El-Kady, M.F.; Sun, J.; Li, Y.; Zhang, Q.; Zhu, M.; Wang, H.; Dunn, B.; Kaner, R.B. Design and mechanisms of asymmetric supercapacitors. Chem. Rev. 2018, 118, 9233-9280.

11. An, T.; Cheng, W. Recent progress in stretchable supercapacitors. J. Mater. Chem. A 2018, 6, 15478-15494. [CrossRef]

12. Wang, F.; Wu, X.; Yuan, X.; Liu, Z.; Zhang, Y.; Fua, L.; Zhu, Y.; Zhou, Q.; Wu, Y.; Huang, W. Latest advances in supercapacitors: From new electrode materials to novel device designs. Chem. Soc. Rev. 2017, 46, 6816-6854. [CrossRef]

13. Han, Y.; Lai, Z.; Wang, Z.; Yu, M.; Tong, Y.; Lu, X. Designing carbon based supercapacitors with high energy density: A summary of recent progress. Chem. Eur. J. 2018, 24, 7312-7329. [CrossRef]

14. Ho, K.-C.; Lin, L.-Y. A review of electrode materials based on core-shell nanostructures for electrochemical supercapacitors. J. Mater. Chem. A 2019, 7, 3516-3530. [CrossRef]

15. Wang, Y.; Xia, Y. Recent progress in supercapacitors: From materials design to system construction. Adv. Mater. 2013, 25, 5336-5342. [CrossRef]

16. Simon, P.; Gogotsi, Y. Materials for electrochemical capacitors. Nat. Mater. 2008, 7, 845-854. [CrossRef] [PubMed]

17. Zhang, K.; Liu, M.; Zhang, T.; Min, X.; Wang, Z.; Chai, L.; Shi, Y. High-performance supercapacitor energy storage using a carbon material derived from lignin by bacterial activation before carbonization. J. Mater. Chem. A 2019, 7, 26838-26848. [CrossRef]

18. Ji, H.; Zhao, X.; Qiao, Z.; Jung, J.; Zhu, Y.; Lu, Y.; Zhang, L.L.; MacDonald, A.H.; Ruoff, R.S. Capacitance of carbon-based electrical double-layer capacitors. Nat. Commun. 2014, 5, 3317. [CrossRef]

19. Zhang, S.-W.; Yin, B.-S.; Liu, X.-X.; Gu, D.-M.; Gong, H.; Wang, Z.-B. A high energy density aqueous hybrid supercapacitor with widened potential window through multi approaches. Nano Energy 2019, 59, 41-49. [CrossRef]

20. Davies, D.M.; Verde, M.G.; Mnyshenko, O.; Chen, Y.R.; Rajeev, R.; Meng, Y.S.; Elliott, G. Combined economic and technological evaluation of battery energy storage for grid applications. Nat. Energy 2019, 4, 42-50. [CrossRef]

21. Kouchachvili, L.; Yaïci, W.; Entchev, E. Hybrid battery/supercapacitor energy storage system for the electric vehicles. J. Power Sources 2018, 374, 237-248. [CrossRef]

22. Hannan, M.A.; Lipu, M.S.H.; Hussain, A.; Mohamed, A. A review of lithium-ion battery state of charge estimation and management system in electric vehicle applications: Challenges and recommendations. Renew. Sustain. Energy Rev. 2017, 78, 834-854. [CrossRef]

23. Wu, X.; Huang, B.; Wang, Q.; Wang, Y. Wide potential and high energy density for an asymmetric aqueous supercapacitor. J. Mater. Chem. A 2019, 7, 19017-19025. [CrossRef]

24. Pal, B.; Yang, S.; Ramesh, S.; Thangadurai, V.; Jose, R. Electrolyte selection for supercapacitive devices: A critical review. Nanoscale Adv. 2019, 1, 3807-3835. [CrossRef]

25. Meng, Q.; Cai, K.; Chen, Y.; Chen, L. Research progress on conducting polymer based supercapacitor electrode materials. Nano Energy 2017, 36, 268-285. [CrossRef]

26. Yu, Z.; Tetard, L.; Zhai, L.; Thomas, J. Supercapacitor electrode materials: Nanostructures from 0 to 3 dimensions. Energy Environ. Sci. 2015, 8, 702-730. [CrossRef] 
27. Xie, K.; Qin, X.; Wang, X.; Wang, Y.; Tao, H.; Wu, Q.; Yang, L.; Hu, Z. Carbon Nanocages as Supercapacitor Electrode Materials. Adv. Mater. 2012, 24, 347-352. [CrossRef]

28. Dutta, S.; Bhaumik, A.; Wu, K.C.-W. Hierarchically porous carbon derived from polymers and biomass: Effect of interconnected pores on energy applications. Energy Enviorn. Sci. 2014, 7, 3574-3592. [CrossRef]

29. Jänes, A.; Kurig, H.; Lust, E. Characterisation of activated nanoporous carbon for supercapacitor electrode materials. Carbon 2007, 45, 1226-1233. [CrossRef]

30. Kesavan, T.; Partheeban, T.; Vivekanantha, M.; Kundu, M.; Maduraiveeran, G.; Sasidharan, M. Hierarchical nanoporous activated carbon as potential electrode materials for high performance electrochemical supercapacitor. Microporous Mesoporous Mater. 2019, 274, 236-244. [CrossRef]

31. Chen, H.; Guo, Y.-C.; Wang, F.; Wang, G.; Qi, P.-R.; Guo, X.-H.; Dai, B.; Yu, F. An activated carbon derived from tobacco waste for use as a supercapacitor electrode material. New Carbon Mater. 2017, 32, 592-599. [CrossRef]

32. Goldfar, J.L.; Dou, G.; Salari, M.; Grinstaff, M.W. Biomass-based fuels and activated carbon electrode materials: An integrated approach to green energy systems. ACS Sustain. Chem. Eng. 2017, 5, 3046-3054. [CrossRef]

33. Lee, J.W.; Lee, H.I.; Park, S.J. Facile synthesis of petroleum-based activated carbons/tubular polypyrrole composites with enhanced electrochemical performance as supercapacitor electrode materials. Electrochim. Acta 2018, 263, 447-453. [CrossRef]

34. Zhi, M.; Yang, F.; Meng, F.; Li, M.; Manivannan, A.; Wu, N. Effects of Pore Structure on Performance of an Activated-Carbon Supercapacitor Electrode Recycled from Scrap Waste Tires. ACS Sustain. Chem. Eng. 2014, 2, 1592-1598. [CrossRef]

35. Wang, C.; Liu, T. Activated carbon materials derived from liquefied bark-phenol formaldehyde resins for high performance supercapacitors. RSC Adv. 2016, 6, 105540-105549. [CrossRef]

36. Qin, B.; Wang, Q.; Zhang, X.; Xie, X.; Jin, L.; Cao, Q. One-pot synthesis of interconnected porous carbon derived from coal tar pitch and cellulose for high-performance supercapacitors. Electrochim. Acta 2018, 283, 655-663. [CrossRef]

37. Ferrero, G.; Fuertes, A.; Sevilla, M. From Soybean residue to advanced supercapacitors. Sci. Rep. 2015, 5, 16618. [CrossRef]

38. Gopalakrishnan, A.; Kong, C.Y.; Badhulika, S. Scalable, large-area synthesis of heteroatom-doped few-layer graphene-like microporous carbon nanosheets from biomass for high-capacitance supercapacitors. New J. Chem. 2019, 43, 1186-1194. [CrossRef]

39. Liu, M.; Niu, J.; Zhang, Z.; Dou, M.; Wang, F. Potassium compound-assistant synthesis of multi-heteroatom doped ultrathin porous carbon nanosheets for high performance supercapacitor. Nano Energy 2018, 51, 366-372. [CrossRef]

40. Genovese, M.; Jiang, J.; Lian, K.; Holmb, N. High capacitive performance of exfoliated biochar nanosheets from biomass saste corn cob. J. Mater. Chem. A 2015, 3, 2903-2913. [CrossRef]

41. Shrestha, R.L.; Shrestha, T.; Tamrakar, B.M.; Shrestha, R.G.; Maji, S.; Ariga, K.; Shrestha, L.K. Nanoporous Carbon Materials Derived from Washnut Seed with Enhanced Supercapacitance. Materials 2020, 13, 2371. [CrossRef]

42. Shrestha, L.K.; Thapa, M.; Shrestha, R.G.; Maji, S.; Pradhananga, R.R.; Ariga, K. Rice husk-derived high surface area nanoporous carbon materials with excellent iodine and methylene blue adsorption properties. C J. Carbon Res. 2019, 5, 10. [CrossRef]

43. Niksiar, A.; Nasernejad, B. Activated carbon preparation from pistachio shell pyrolysis and gasification in a spouted bed reactor. Biomass Bioenergy 2017, 106, 43-50. [CrossRef]

44. Li, J.; Wu, Q. Water bamboo-derived porous carbons as electrode materials for supercapacitors. New J. Chem. 2015, 39, 3859-3864. [CrossRef]

45. Gao, F.; Geng, C.; Xiao, N.; Qu, J.; Qiu, J. Hierarchical porous carbon sheets derived from biomass containing an activation agent and in-built template for lithium ion batteries. Carbon 2018, 139, 1085-1092. [CrossRef]

46. Pourhosseini, S.E.M.; Norouzi, O.; Salimi, P.; Naderi, H.R. Synthesis of a novel interconnected 3D pore network algal biochar constituting iron nanoparticles derived from a harmful marine biomass as high-performance asymmetric supercapacitor electrodes. ACS Sustain. Chem. Eng. 2018, 6, 4746-4758. [CrossRef]

47. Wei, X.; Li, Y.; Gao, S. Biomass-derived interconnected carbon nanoring electrochemical capacitors with high performance in both strongly acidic and alkaline electrolytes. J. Mater. Chem. A 2017, 5, 181-188. [CrossRef] 
48. Yuan, G.; Huang, W.; Guan, K.; Li, H.; Xie, Y.; Liang, Y.; Liu, Y.; Zheng, M. A universal KOH-free strategy towards nitrogen doped carbon nanosheets for high-rate and high energy storage devices. J. Mater. Chem. A 2019, 7, 26469-26478. [CrossRef]

49. Shrestha, L.K.; Shrestha, R.G.; Maji, S.; Pokahrel, B.P.; Rajbhandari, R.; Shrestha, R.L.; Pradhananga, R.R.; Hill, J.P.; Ariga, K. High surface area nanoporous graphitic carbon materials derived from Lapsi seed with enhanced supercapacitance. Nanomaterials 2020, 10, 728. [CrossRef]

50. Wei, L.; Yushin, G. Nanostructured activated carbons from natural precursors for electrical double layer capacitors. Nano Energy 2012, 1, 552-565. [CrossRef]

51. Wang, R.; Wang, P.; Yan, X.; Lang, J.; Peng, C.; Xue, Q. Promising porous carbon derived from celtuce leaves with outstanding supercapacitance and $\mathrm{CO}_{2}$ capture performance. ACS Appl. Mater. Interfaces 2012, 4, 5800-5806. [CrossRef] [PubMed]

52. Feng, P.; Li, J.; Wang, H.; Xu, Z. Biomass-based activated carbon and activators: Preparation of activated carbon from corncob by chemical activation with biomass pyrolysis liquids. ACS Omega 2020, 5, 24064-24072. [CrossRef]

53. Prauchner, M.J.; Sapag, K.; Rodríguez-Reinosoc, F. Tailoring biomass-based activated carbon for $\mathrm{CH}_{4}$ storage by combining chemical activation with $\mathrm{H}_{3} \mathrm{PO}_{4}$ or $\mathrm{ZnCl}_{2}$ and physical activation with $\mathrm{CO}_{2}$. Carbon 2016, 110, 138-147. [CrossRef]

54. Seaton, N.A.; Walton, J.P.R.B.; Quirke, N. A new analysis for the determination of the pore size distribution of porous carbons from nitrogen adsorption measurements. Carbon 1989, 27, 853-861. [CrossRef]

55. Lastoskie, C.; Gubbins, K.E.; Quirke, N. Pore size distribution analysis of microporous carbons: A density functional theory approach. J. Phys. Chem. 1993, 97, 4786-4796. [CrossRef]

56. Landers, J.; Gor, G.Y.; Neimark, A.V. Density functional theory methods for characterization of porous materials. Colloids Surf. A 2013, 437, 3-32. [CrossRef]

57. Zhu, Y.; Murali, S.; Stoller, M.D.; Ganesh, K.J.; Cai, W.; Ferreira, P.J.; Pirkle, A.; Wallace, R.M.; Cychosz, K.A.; Thommes, M.; et al. Carbon-based supercapacitors produced by activation of graphene. Science 2011, 332, 1537-1541. [CrossRef]

58. Hirst, E.A.; Taylor, A.; Mokaya, R. A simple flash carbonization route for conversion of biomass to porous carbons with high $\mathrm{CO}_{2}$ storage capacity. J. Mater. Chem. A 2018, 6, 12393-12403. [CrossRef]

59. Tang, J.; Wang, J.; Shrestha, L.K.; Hossain, S.A.; Alothman, Z.A.; Yamauchi, Y.; Ariga, K. Activated porous carbon spheres with customized mesopores through assembly of diblock copolymers for electrochemical capacitor. ACS Appl. Mater. Interfaces 2017, 9, 18986-18993. [CrossRef]

60. Lee, J.-S.M.; Briggs, M.E.; Hu, C.-C.; Cooper, A.I. Controlling electric double-layer capacitance and pseudocapacitance in heteroatom-doped carbons derived from hypercrosslinked microporous polymers. Nano Energy 2018, 46, 277-289. [CrossRef]

61. Wang, Y.; Song, Y.; Xia, Y. Electrochemical capacitors: Mechanism, materials, systems, characterization and applications. Chem. Soc. Rev. 2016, 45, 5925-5950. [CrossRef]

62. Shrestha, L.K.; Adhikari, L.; Shrestha, R.G.; Adhikari, M.P.; Ahikari, R.; Hill, J.P.; Pradhananga, R.R.; Ariga, K. Nanoporous carbon materials with enhanced supercapacitance performance and non-aromatic chemical sensing with C1/C2 alcohol discrimination. Sci. Technol. Adv. Mater. 2016, 17, 483-492. [CrossRef]

63. Magana, J.R.; Kolen'ko, Y.V.; Deepak, F.L.; Solans, C.; Shrestha, R.G.; Hill, J.P.; Ariga, K.; Shrestha, L.K.; Rodriguez-Abreu, C. From chromonic self-assembly to hollow carbon nanofibers: Efficient materials in supercapacitor and vapor-sensing applications. ACS Appl. Mater. Interface 2016, 8, 31231-31238. [CrossRef]

64. Gogotsi, Y.; Simon, P. True performance metrics in electrochemical energy storage. Science 2011, 334, 917-918. [CrossRef] [PubMed]

65. Chmiola, J.; Largeot, C.; Taberna, P.-L.; Simon, P.; Gogotsi, Y. Monolith carbide-derived carbon films for micro-supercapacitors. Science 2010, 328, 480-483. [CrossRef] [PubMed]

Publisher's Note: MDPI stays neutral with regard to jurisdictional claims in published maps and institutional affiliations. 